\title{
Emotional AI and Freedom of Thought
}

\author{
Ho Manh Tung \\ Ritsumeikan Asia Pacific University, \\ Beppu, Oita, Japan
}

December 11, 2020

We live in a world permeated with machines and algorithms that are getting better at tracking our emotional lives (McStay, 2018). Originated from the development of affective computing (Picard, 2000), the field of emotional artificial intelligence (emotional AI) has made great progress with the explosion of big data. And these technologies will only get better, given the commercial (Zuboff, 2015) and political interests (Bakir, 2020). In this essay, I list five ways emotional AI technologies interfere with our freedom of thought. Freedom of thoughts can be defined as freedom from manipulation and coercion. According to many thinkers, the right to freedom of thought is the foundation of democracy.

1) Optimal "hijacking of our attention:" The basic truth about the algorithms behind social media and other modern computational platforms is that they are optimized to hijack our attention (O'neil, 2016). What we pay attention to largely determines what we think, what we feel, how we feel about things. Thus, manipulating our attention is an infringement of our right to freedom of thoughts and freedom of choice.

2) Interfering with our emotions is interfering with our counterfactual reasoning: Our emotions play a very important role in helping us to reason through all the counterfactuals (Pearl, 
2019, Vuong et al., 2020), which I think is essential to our freedom of thoughts and freedom of choice.

\section{3) The networked nature of these platforms means certain emotions are quickly} amplified and spread. It seems that fear, anxiety, and outrage spread quickly on social media (Crocket, 2017; Rice, 2020). In a climate of fear, anxiety, and outrage, it will be harder to think for yourself, to say what you think. In a climate of fear, anxiety, and outrage, it is harder to go against our preconceived models of the world, to dispassionately evaluate new ideas. Moreover, the networked nature of these platforms lead o

4) A more sophisticated form of a society of control: The harvesting of non-conscious data on emotions and using it to manipulate human behaviors seem to be aligned with the mechanisms of Deleuze's society of control (Deleuze, 1992). In a society of control, people lose their individuality and become self-policing cogs in a machine.

5) The concerns over the inaccuracy and bias in emotional AI: Most emotional AI algorithms seem to be designed with the underlying Paul Ekman's Universal Emotion Hypothesis (Ekman, 1999). This hypothesis has been challenged intensely with new empirical results from cognitive science (Gendron, Crivelli \& Barrett, 2018; Barrett, 2017; Barrett et al., 2019). Inaccurate and biased tracking of our emotions can lead to mistaken decision-making.

These issues raise the importance of discussing legal and socio-cultural institutions to govern emotional AI technologies' growing influence on psychology. As all of these technologies originate from academic research, it is important for the academic community to tackle this problem head-on. Several proposals to regulate these technological developments have been proposed. For example, Brent Hecht proposed in 2018 that peer-reviewers must 
ensure computer scientists to include statements on the negative societal consequences of their work (Gibney, 2018); or a proposal on stricter regulation at ethical checkpoints such as peerreviews, journals, and conferences editors, etc. (Van Noorden, 2020). In this new intellectual terrains, ethicists, sociologists, and engineers need to work together in the spirit of openness, transparency, and humility (Vuong, 2017; 2018; 2019; 2020).

\section{References}

Bakir, V. (2020). Psychological Operations in Digital Political Campaigns: Assessing Cambridge Analytica's Psychographic Profiling and Targeting. Frontiers in Communication, 5, 67. doi:10.3389/fcomm.2020.00067

Barrett, L. F. (2017). The theory of constructed emotion: an active inference account of interoception and categorization. Social Cognitive and Affective Neuroscience, 12(1), 123. doi:10.1093/scan/nsw 154

Barrett, L. F., Adolphs, R., Marsella, S., Martinez, A. M., \& Pollak, S. D. (2019). Emotional Expressions Reconsidered: Challenges to Inferring Emotion From Human Facial Movements. Psychological Science in the Public Interest, 20(1), 1-68. doi:10.1177/1529100619832930

Crockett, M. J. (2017). Moral outrage in the digital age. Nature Human Behaviour, 1(11), 769771.

Deleuze, G. (1992). Postscript on the Societies of Control. October, 59, 3-7.

Ekman, P. (1999). Basic Emotions. In T. Dalgleish \& M. Power (Eds.), Handbook of Cognition and Emotion. Sussex, UK: John Wiley \& Sons. 
Gendron, M., Crivelli, C., \& Barrett, L. F. (2018). Universality Reconsidered: Diversity in Making Meaning of Facial Expressions. Current Directions in Psychological Science, 27(4), 211-219. doi:10.1177/0963721417746794

Gibney, E. (July 26, 2018). The ethics of computer science: this researcher has a controversial proposal. Nature: News $Q \& A$. Retrieved from https://www.nature.com/articles/d41586018-05791-w

O'neil, C. (2016). Weapons of math destruction: How big data increases inequality and threatens democracy. New York: Broadway Books.

Pearl, J. (2019). The seven tools of causal inference, with reflections on machine learning. Communications of the ACM, 62(3), 54-60.

Rice, J. (2020). Algorithmic outrage. Computers and Composition, 57, 102582.

Van Noorden, R. (2020). The ethical questions that haunt facial-recognition research. Nature, 587(354-358). doi:https://doi.org/10.1038/d41586-020-03187-3

Vuong, Q. H. (2017). Open data, open review and open dialogue in making social sciences plausible. Nature: Scientific Data Updates. (December 12, 2017). Retrieved from: https://go.nature.com/37y6nn0

Vuong, Q. H. (2018). The (ir) rational consideration of the cost of science in transition economies. Nature Human Behaviour, 2(1), 5.

Vuong, Q. H. (2019). Breaking barriers in publishing demands a proactive attitude. Nature Human Behaviour, 3(10), 1034. 
Vuong, Q. H. (2020). Reform retractions to make them more transparent. Nature, 582(7811), 149.

Vuong, Q.-H., Ho, M.-T., Nguyen, H.-K. T., et al. (2020). On how religions could accidentally incite lies and violence: folktales as a cultural transmitter. Palgrave Communications, 6(1), 82. doi:10.1057/s41599-020-0442-3 